\title{
Microphysical and radiative effects of aerosols on warm clouds during the Amazon biomass burning season as observed by MODIS: impacts of water vapor and land cover
}

\author{
J. E. Ten Hoeve ${ }^{1}$, L. A. Remer ${ }^{2}$, and M. Z. Jacobson ${ }^{1}$ \\ ${ }^{1}$ Department of Civil and Environmental Engineering, Stanford University, CA, USA \\ ${ }^{2}$ NASA Goddard Space Flight Center, Greenbelt, MD, USA
}

Received: 3 June 2010 - Published in Atmos. Chem. Phys. Discuss.: 25 October 2010

Revised: 31 January 2011 - Accepted: 15 March 2011 - Published: 1 April 2011

\begin{abstract}
Aerosol, cloud, water vapor, and temperature profile data from the Moderate Resolution Imaging Spectroradiometer (MODIS) are utilized to examine the impact of aerosols on clouds during the Amazonian biomass burning season in Rondônia, Brazil. It is found that increasing background column water vapor (CWV) throughout this transition season between the Amazon dry and wet seasons likely exerts a strong effect on cloud properties. As a result, proper analysis of aerosol-cloud relationships requires that data be stratified by CWV to account better for the influence of background meteorological variation. Many previous studies of aerosol-cloud interactions over Amazonia have ignored the systematic changes to meteorological factors during the transition season, leading to possible misinterpretation of their results. Cloud fraction (CF) is shown to increase or remain constant with aerosol optical depth (AOD), depending on the value of $\mathrm{CWV}$, whereas the relationship between cloud optical depth (COD) and AOD is quite different. COD increases with AOD until AOD $\sim 0.3$, which is assumed to be due to the first indirect (microphysical) effect. At higher values of AOD, COD is found to decrease with increasing AOD, which may be due to: (1) the inhibition of cloud development by absorbing aerosols (radiative effect/semi-direct effect) and/or (2) a possible retrieval artifact in which the measured reflectance in the visible is less than expected from a cloud top either from the darkening of clouds through the addition of carbonaceous biomass burning aerosols within or above clouds or subpixel dark surface contamination in the measured cloud reflectance. If (1) is a contributing mechanism, as we suspect, then an empirically-derived increasing func-
\end{abstract}

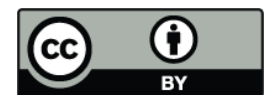

Correspondence to: J. E. Ten Hoeve (tenhoeve@stanford.edu) tion between cloud drop number and aerosol concentration, assumed in a majority of global climate models, is inaccurate since these models do not include treatment of aerosol absorption in and around clouds. The relationship between aerosols and both CWV and clouds over varying land surface types is also analyzed. The study finds that the difference in CWV between forested and deforested land is not correlated with aerosol loading, supporting the assumption that temporal variation of CWV is primarily a function of the largerscale meteorology. However, a difference in the response of CF to increasing AOD is observed between forested and deforested land. This suggests that dissimilarities between other meteorological factors, such as atmospheric stability, may have an impact on aerosol-cloud correlations between different land cover types.

\section{Introduction}

The effect of aerosol particles on the hydrological cycle remains one of the largest uncertainties in the understanding of Earth's climate system. Biomass burning, from both deforestation and annual agricultural burning, is the largest anthropogenic source of such particles in the Southern Hemisphere. A variety of observational and modeling studies have examined the effect of aerosols on the regional hydrometeorology over the Amazon Basin during the biomass burning season (Kaufman and Nakajima, 1993; Kaufman and Fraser, 1997; Koren et al., 2004, 2008; Feingold et al., 2005; Yu et al., 2007; Zhang et al., 2008, 2009; Martins et al., 2009). Biomass burning aerosols have been shown to affect clouds through both microphysical and radiative mechanisms (Kaufman et al., 2005a, 2008; Kaufman and Koren,

Published by Copernicus Publications on behalf of the European Geosciences Union. 
2006; Rosenfeld et al., 2008). Depending on the concentration of aerosol, its chemical composition, size distribution, vertical distribution relative to clouds, and the background cloud characteristics, biomass burning aerosols are suggested either to inhibit or invigorate cloud formation and/or growth (Feingold et al., 2005; Koren et al., 2008).

Carbonaceous biomass burning aerosols can absorb solar radiation, warming the aerosol layer and reducing the radiation reaching the surface (Ackerman et al., 2000; Kaufman et al., 2002; Koren et al., 2004). This effect cools the surface, increases the static stability of the lower troposphere, suppresses surface heat and moisture fluxes, and slows the hydrological cycle (Jacobson, 2002; Ramanathan et al., 2005). Evaporation of clouds within the aerosol layer may also occur due to the increase in temperature and decrease in relative humidity caused by aerosol absorption of solar radiation (Yu et al., 2002; Jacobson, 2006). Referred to as absorption effects or the semi-direct effect, these radiative processes primarily suppress the formation and growth of clouds.

Microphysical effects, on the other hand, enhance cloud formation and growth. Biomass burning aerosols are hygroscopic and can serve as cloud condensation nuclei (Feingold et al., 2001; Andreae et al., 2002, 2004). Expansion chamber experiments have shown that the addition of cloud condensation nuclei will nucleate a larger number of smaller cloud droplets, and these droplets are therefore slower to coalesce to form precipitation (Gunn and Phillips, 1957; Squires et al., 1958). These aerosol-processed clouds are also more reflective, exhibit changed drizzle properties, and have been suggested to have longer lifetimes (Twomey, 1977; Albrecht, 1989). However, the apparent darkening of clouds by absorptive biomass burning aerosols has also been observed by satellite (Kaufman and Nakajima, 1993; Wilcox et al., 2009). Recent studies have shown that these polluted clouds may become invigorated with higher liquid or ice water paths and lower cloud top pressures (Andreae et al., 2004; Khain et al., 2005; Koren et al., 2005; Lin et al., 2006; Koren et al., 2008; Rosenfeld et al., 2008; Meskhidze et al., 2009). The delay of raindrop formation in polluted clouds suppresses downdrafts, which allows for the generation of greater updrafts and stronger convection. The updrafts carry water vapor to higher altitudes, where additional energy from the latent heat of freezing may be released, further invigorating convection (Williams et al., 2002; Andreae et al., 2004; Rosenfeld et al., 2008). Increases in aerosol optical depth (AOD) have also been linked to increases in cloud fraction (CF), particularly at low AODs (Kaufman et al., 2005a; Koren et al., 2005; Lin et al., 2006; Myhre et al., 2007).

More recent studies have illustrated that there may be a smooth transition between these competing microphysical and radiative effects (Koren et al., 2008; Rosenfeld et al., 2008). Using MODIS data over the Amazon, Koren et al. (2008) hypothesized that microphysical processes dominate at lower AODs, increasing CF and cloud top height, whereas radiative processes dominate at higher AODs, de- creasing CF and cloud top height. The study also showed that the relative contributions of the microphysical and radiative effects are strongly tied to the initial CF prior to the influence of aerosols - the radiative absorption effect begins to dominate at lower values of AOD for lower initial cloud fractions. This is due to the hypothesized aerosol absorption cloud fraction feedback: stabilization of the near-surface atmosphere due to aerosol absorption of radiation initially reduces cloudiness, which then exposes more of the aerosol layer, further reducing cloudiness (Koren et al., 2008). This reduction in cloudiness has also been described as a black carbon-low cloud positive feedback loop (Jacobson, 2002). For low cloud fractions, more of the aerosol layer is available for absorption, resulting in a stronger feedback. For higher cloud fractions, microphysical invigoration will dominate for the same degree of aerosol loading. An implication of this finding is that aerosol effects on either sparse or dense cloud fields may have opposite effects on climate forcing.

For the majority of observational biomass burning studies over the Amazon, the months of August, September, and October are typically selected due to the combination of high aerosol loading from biomass burning and relatively consistent dry conditions present during these months. High pressure typically remains over the region throughout the dry season (Southern Hemisphere winter) into mid-to-late October, when the onset of the rainy season begins (Nobre et al., 1998). Small cumulus clouds often form at the top of the atmospheric boundary layer, which is constrained by a subsidence inversion. The majority of biomass burning smoke exists at or below the cloud layer at an approximate altitude of 3-km (Davidi et al., 2009), although occasionally smoke plumes are pumped to higher altitudes through deeper cumulus convection. Higher cold clouds, decoupled from the smoke below, also occur at times. The timescale of cumulus clouds in our region of interest is on the order of minutes, yet these clouds are organized into cloud fields that have a much longer duration, influenced by surface properties as well as local mesoscale and larger circulations. Cloud fields generally form by noon and dissipate overnight throughout the Amazon Basin (Koren et al., 2004; Negri et al., 2004). Aerosol loading, conversely, may vary on longer weekly time scales even if source fires vary diurnally (Giglio, 2007). Biomass burning smoke can build over many diurnal cycles and thus become more homogenous both temporally and spatially than the individual clouds or cloud fields.

In some studies of aerosol-cloud interactions, variations of cloud properties are assumed to be weakly dependent on meteorology due to the stationary high pressure systems present during the South American biomass burning season (Kaufman and Nakajima 1993; Koren et al., 2004, 2008). However, our study illustrates that gradually increasing background column water vapor (CWV) during the biomass burning transition season between the end of the dry season and the beginning of the wet season, has a discernable impact on aerosol-cloud relationships. Previous studies have noted 
that aerosol loading and CWV are weakly spatially correlated over the Amazon Basin on seasonal timescales (Feingold et al., 2001). On smaller spatial and temporal scales, latitudinal variation of both CWV and AOD will produce high correlations in some areas (Kaufman and Fraser, 1997). Regions where simultaneous advection of these two parameters takes place also exhibit high correlations (Remer et al., 1998). Variability in CWV, which can be observed daily and at moderately high spatial resolution using the MODIS sensor, may be also used as a tracer for large-scale meteorological variability. Attempts to remove the influence of meteorology from aerosol-cloud correlations are common (Koren et al., 2005; Lin et al., 2006; Yu et al., 2007). Here, we use $\mathrm{CWV}$, which is also shown to correlate with MODIS cloud parameters, to stratify the cloud data to ensure similar background moisture conditions exist along the range of AOD retrievals used.

The latter portion of the paper tests the assumption that CWV is not influenced by aerosol loading, which is assumed in the former portion of the paper, by analyzing effects of aerosols on CWV and clouds over different land surface types. Many studies have probed the local effects of deforestation on local and regional meteorology; however, no observational studies have analyzed the aerosol effect on clouds over both forested and deforested land. Studies have examined the regional climate effects of deforestation through changes in surface energy and water vapor fluxes and land-atmosphere interactions (Henderson-Sellers and Gornitz, 1984; Nobre et al., 1991; Cutrim et al., 1995; Wang et al., 2000, 2009; Roy and Avissar, 2002; Negri et al., 2004). Regional-scale deforestation has been shown to result in mesoscale circulations that arise from land surface heterogeneities (Segal et al., 1988; Wang et al., 2000, 2009; Roy et al., 2002). Enhanced shallow convection over deforested regions is caused in part by an inland breeze from nearby moisture-rich forests. When this moist inland breeze reaches unstable air over the deforested region (due to greater surface heating), it rises to form clouds (Segal et al., 1988; Roy et al., 2002). Several observational studies have shown an increase in shallow convection over disturbed regions of the Amazon due to this direct thermal circulation, particularly in the state of Rondônia, Brazil (Cutrim et al., 1995; Durieux et al., 2003; Negri et al., 2004; Wang et al., 2009). Our study differs from previous studies in that the aerosol effect on water vapor and clouds over forested and deforested land is examined - a logical extension of the studies noted above. This study investigates two primary questions: (1) how can physical aerosol-cloud relationships be extracted from the seasonal progression of CWV, CF, and AOD and (2) how can further differences in these aerosol-cloud relationships be extracted between forested and deforested land cover types?

\section{Data and methods}

MODIS, onboard the Terra and Aqua satellites, provides relatively high spatial resolution (250-m-500-m) while achieving near global coverage on a daily basis (Salomonson et al., 1989). The daytime Aqua overpass (13:30 LT) is chosen over the Terra overpass (10:30 LT) since clouds are more likely to be developed in the afternoon than the morning. This study employs MODIS swath Level 2 aerosol, cloud, water vapor, and temperature products (King et al., 2003).

Aerosol optical depth is calculated over land and ocean at a wavelength of $550 \mathrm{~nm}$ and is provided at $10-\mathrm{km} \times 10-\mathrm{km}$ resolution (Remer et al., 2005; Levy et al., 2010). Validation with ground-based AERONET observations yields an overall error of $\pm 0.05 \pm 0.15 \tau_{\mathrm{a}}$ over land, where $\tau_{\mathrm{a}}$ is the aerosol optical depth at $550 \mathrm{~nm}$ (Levy et al., 2010). Level 2 cloud fraction and cloud top pressure are produced at 5$\mathrm{km} \times 5-\mathrm{km}$ resolution, whereas cloud optical depth is produced at $1-\mathrm{km} \times 1-\mathrm{km}$ resolution (Platnick et al., 2003). The $5-\mathrm{km}$ cloud fraction product is computed using the fraction of $1-\mathrm{km}$ cloudy pixels in the $5-\mathrm{km}$ footprint, as determined by the cloud mask product (Platnick et al., 2003). Cloud optical depth is inversely calculated from spectral reflectance measurements and surface albedo data by using a lookup table (Nakajima and King, 1990; Platnick et al., 2003). For over-land retrievals, cloud optical depth is calculated at wavelengths $0.645 \mu \mathrm{m}$ and $2.130 \mu \mathrm{m}$. A drawback of the MODIS sensor is that it cannot discern the vertical location of aerosols or the physical thickness of clouds. As a result, additional sensors (e.g. the CALIPSO lidar) are required to study the vertical distribution of clouds and aerosols (Winker et al., 2003).

Column water vapor (precipitable water vapor) from the MOD07 profile product is provided at $5-\mathrm{km} \times 5-\mathrm{km}$ resolution in units of centimeters of equivalent liquid water (Seemann et al., 2003). We choose not to use the near-IR column water vapor product due to its limitations over dark surfaces (Gao and Kaufman, 2003). Temperature profile observations are also employed from the MOD07 product to estimate lowlevel stability (Seemann et al., 2003). Since surface pressure is often below $1000 \mathrm{hPa}$, the temperature at $1000 \mathrm{hPa}$ is calculated using the skin temperature, surface pressure, and Poisson's equation for potential temperature. Skin temperature is not the best approximation for surface air temperature; however, for the purposes of finding relative differences in atmospheric stability across our study domain, we believe this is our best option considering that a high-resolution observational surface temperature data set is currently not available from any other source.

Data from the cloud, water vapor, and temperature products, which are provided at resolutions between 1-km and 5$\mathrm{km}$, are averaged to a resolution of $10-\mathrm{km} \times 10-\mathrm{km}$ in order to conform to the Level 2 aerosol data. We create an aggregated product with multiple satellite parameters at a scale which is considerably finer than the $1^{\circ} \times 1^{\circ}$ Level 3 product. 
Products requiring a clear sky, such as the atmospheric profile products, are able to be estimated for a significant number of $10-\mathrm{km}$ pixels with cloud fractions less than one.

In the first portion of the paper, aerosol and cloud data over all non-water surfaces are included in the analyses. In the latter portion of the paper, MODIS aerosol, cloud, stability, and water vapor data are stratified by land cover type. This requires an up-to-date, high-resolution land cover classification data set. The Land Processes Distributed Active Archive Center (LP DAAC), located at the US Geological Survey (USGS) Earth Resources Observation and Science (EROS) Center, provides a combined Terra/Aqua yearly land cover product - MCD12Q1 (http://lpdaac.usgs.gov). This product employs decision tree classification algorithms and training data to assign land cover classifications (Friedl et al., 2010). The data are resampled from $500-\mathrm{m} \times 500-\mathrm{m}$ resolution to $0.1^{\circ} \times 0.1^{\circ}$ resolution to approximately match the resolution of the Level 2 swath aerosol data.

Our $5^{\circ} \times 5^{\circ}$ study region encompasses the deforested region of Ji Paraná in Rondônia, Brazil, as well as a protected forest to the east, illustrated in Fig. 1. Broad-leaf forest classifications are assigned to the forested category, whereas closed shrublands, open shrublands, woody savannas, savannas, grasslands, croplands, cropland and natural vegetation mosaic, and barren or sparsely vegetated classifications are assigned to the deforested (pasture) category, according to the International Geosphere-Biosphere Programme categorization scheme (Friedl et al., 2010). The percentage of deforested land increases from year to year in our fixed study region due to ongoing forest conversion activities.

A small region is chosen for this study, compared with other studies of its type, so that meteorological differences due to spatial variation will be better removed, and so that stratification of atmospheric data by land cover type can be conducted. The high spatial resolution of the Level 2 data allows for the accumulation of a sufficient data record for analysis, while also reducing the pixel size in which aerosol and cloud characteristics need to be assumed constant. The study encompasses the Amazonian biomass burning months of $\mathrm{Au}-$ gust, September and October for the years 2004 through 2007. This time period includes both dry and wet years, as well as years with both heavy and light biomass burning, according to NCEP/NCAR Reanalysis data and MODIS data (Kalnay et al., 1996; Koren et al., 2007). The aerosol effect on cloud properties over the Amazon has been shown to differ in a humid year compared to a dry year (Yu et al., 2007). The inclusion of multiple years reduces the interannual variability present in the data, and also allows for the compilation of a large enough data set for analysis in our small study region.

Retrievals that are not considered "useful" or are considered "bad" quality according to the Level 2 quality assurance bit data are removed. To account further for meteorological variability, NCEP/NCAR Reanalysis $700 \mathrm{hPa}$ wind vectors are used to remove days for which high pressure was not

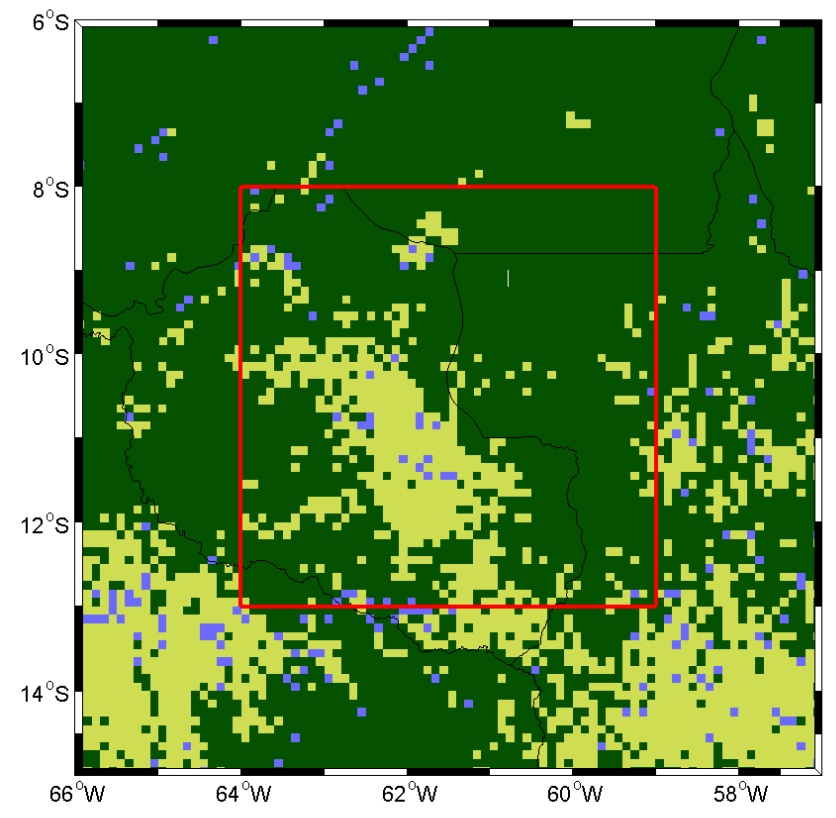

Fig. 1. Land cover classifications for the year 2004. Dark green pixels represent evergreen forests and light green pixels represent deforested land (pasture). Blue pixels represent land classifications that are not included in either of these two categories. The $5^{\circ} \times 5^{\circ}$ study region is outlined with a red box. On average between 2004 and 2007 , roughly $73 \%$ of our study region is classified as forested land and $25 \%$ of our study region is classified as deforested land.

the dominant weather pattern over the region (Kalnay et al., 1996). The anti-cyclonic high pressure circulation is found to be most discernable at $700 \mathrm{hPa}$ in the NCEP/NCAR Reanalysis data, however, lower level (e.g. $850,925 \mathrm{hPa}$ ) wind vectors may also be used since high pressure extends throughout the troposphere. By removing these anomalous days, cloud fields are more likely to be similar among all days analyzed, even though the structure and morphology of these clouds are already similar throughout this season (Koren et al., 2004). We removed a total of 43 days during our study period, equaling $12 \%$ of the total number of days in August through October between 2004 and 2007. We restrict the number of cloud types analyzed by choosing to study only warm clouds. Warm clouds are segregated from cold and unknown-phase clouds by only retaining $10-\mathrm{km}$ pixels that contain $>95 \%$ of $1-\mathrm{km}$ cloud retrievals in the liquid water phase. We have retained a total of 368288 warm cloud and clear sky retrievals over our domain and study period. The re-sampled 10-km atmospheric aerosol, cloud, and profile data are then segregated by forested and deforested land cover types in the latter portion of the paper to explore the effect of land-atmosphereaerosol interactions on column water vapor and clouds.

Aerosol optical depth and column water vapor MODIS satellite retrievals are compared with Aerosol Robotic Network (AERONET) automatic sun/sky radiometer measurements in Fig. 2 (Holben et al., 1998). Data represent two 
stations within the $5^{\circ} \times 5^{\circ}$ study region, Abracos Hill, active in 2004 and 2005, and Ji Paraná SE, active in 2006 and 2007. Only days that fall within our study period are included. Correlation coefficients between MODIS retrievals and AERONET measurements are above 0.90 for both aerosol optical depth and column water vapor, providing confidence in the MODIS satellite retrievals.

\section{Results}

\subsection{Effect of water vapor variability on aerosol-cloud interactions}

Column water vapor (CWV) increases over our study region throughout the dry-to-wet transition season between the months of August to October. Figure 3a shows MODIS CWV and warm cloud fraction (CF) averaged into eight equally-spaced bins between 1 August and 31 October, for all years between 2004 and 2007. CF and CWV are understandably highly positively correlated, as water vapor is one of the principal components required for cloud formation. Figure $3 b$ shows MODIS aerosol optical depth (AOD) at $550 \mathrm{~nm}$, also binned by day of the season. Unlike CWV, AOD increases from 1 August until approximately the middle of September, at which point the relationship reverses and decreases until the end of the season on 31 October. This mid-season peak in aerosol loading is indicative of a biomass burning peak that is largely determined by social behavior (Crutzen and Andreae, 1990). Burning usually occurs late enough into the season to sufficiently allow vegetation to dry out, but not too late to risk an early onset of the rainy season.

In Fig. 3a, b, only retrievals with AODs less than or equal to 0.8 are included in the time series. Time series of CWV, $\mathrm{CF}$, and AOD utilizing the entire range of AODs behaves similarly to the time series in Fig. 3a, b. AODs are restricted to below 0.8 for the remainder of the analysis to prevent aerosol misclassification as cloud (Brennan et al., 2005). In this range, significant cloud contamination of aerosol is also unlikely, yet occasional contamination may still occur (Kaufman et al., 2005b). Koren et al. (2010) found that MODIS aerosol-cloud relationships over the tropical Atlantic were likely affiliated with physical mechanisms and not retrieval artifacts, suggesting that the relationships found in our study may also be physically-based. It is also improbable that these correlations are due to a 3-D cloud effect, which artificially increases AOD retrievals in the regions neighboring clouds (Wen et al., 2006). This effect has been suggested to be larger for greater cloud cover and aerosol loading, but our results indicate that the strongest positive correlation between $\mathrm{CF}$ and AOD occurs at lower values of AOD and cloud cover (see discussion of Fig. 4 below) (Wen et al., 2006; Yu et al., 2007).
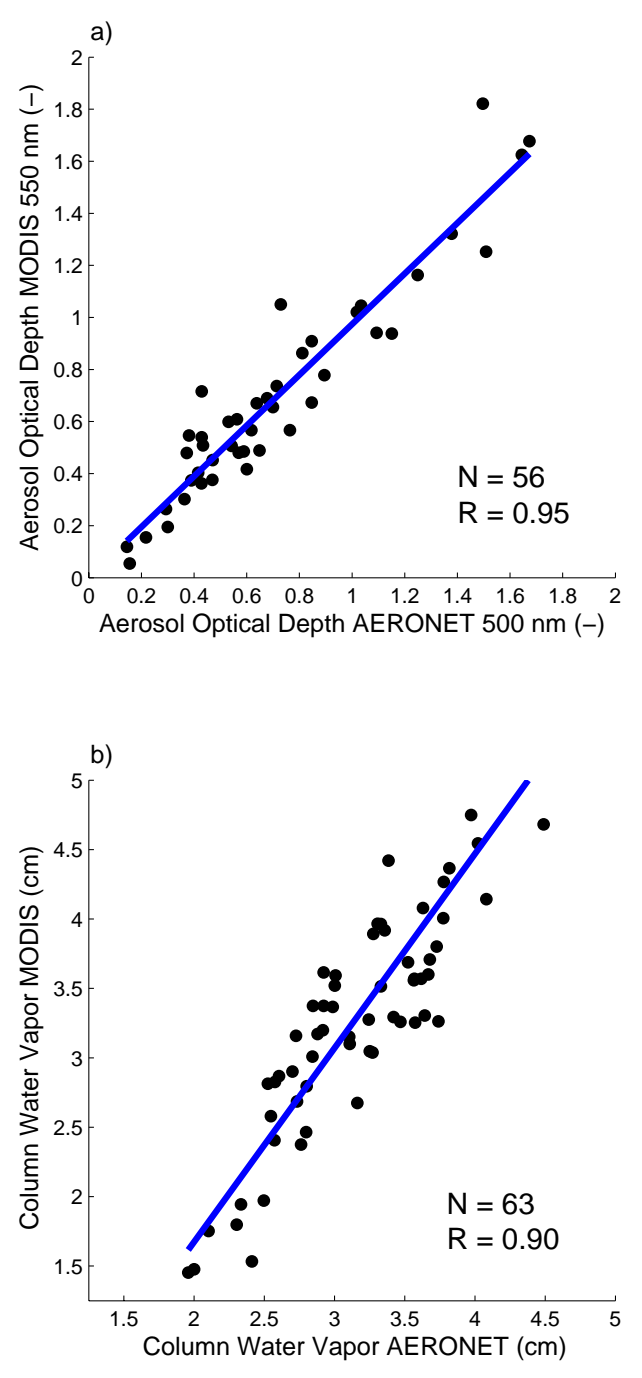

Fig. 2. (a) Comparison of co-located MODIS aerosol optical depth retrievals with Aerosol Robotic Network (AERONET) measurements at Abracos Hill $\left(62.358^{\circ} \mathrm{W}, 10.760^{\circ} \mathrm{S}\right)$ and Ji Paraná SE $\left(61.852^{\circ} \mathrm{W}, 10.934^{\circ} \mathrm{S}\right)$ for days used in the study during the months of August through October, for the years 2004 through 2007. These two sites are located within our $5^{\circ} \times 5^{\circ}$ study region. (b) Comparison of co-located Level 2 MODIS column water vapor retrievals with AERONET measurements for the same time period as in (a). The number of points $(N)$ in each plot and correlation coefficients $(R)$ between MODIS and AERONET data are also included. For each point, MODIS retrievals centered within 15$\mathrm{km}$ of the AERONET station are averaged and compared with 1$\mathrm{h}$ temporally-averaged AERONET data $( \pm 30 \mathrm{~min}$ from the mean MODIS retrieval time).

Figure 3 indicates that $\mathrm{CWV}$ and $\mathrm{CF}$ are directly correlated with AOD during the first half of the season, whereas these variables are inversely correlated during the second half of the season. Thus, if we plot CWV and CF directly against AOD, separated into the two halves of the season, we would expect the signs of the regression slopes to be the same for 

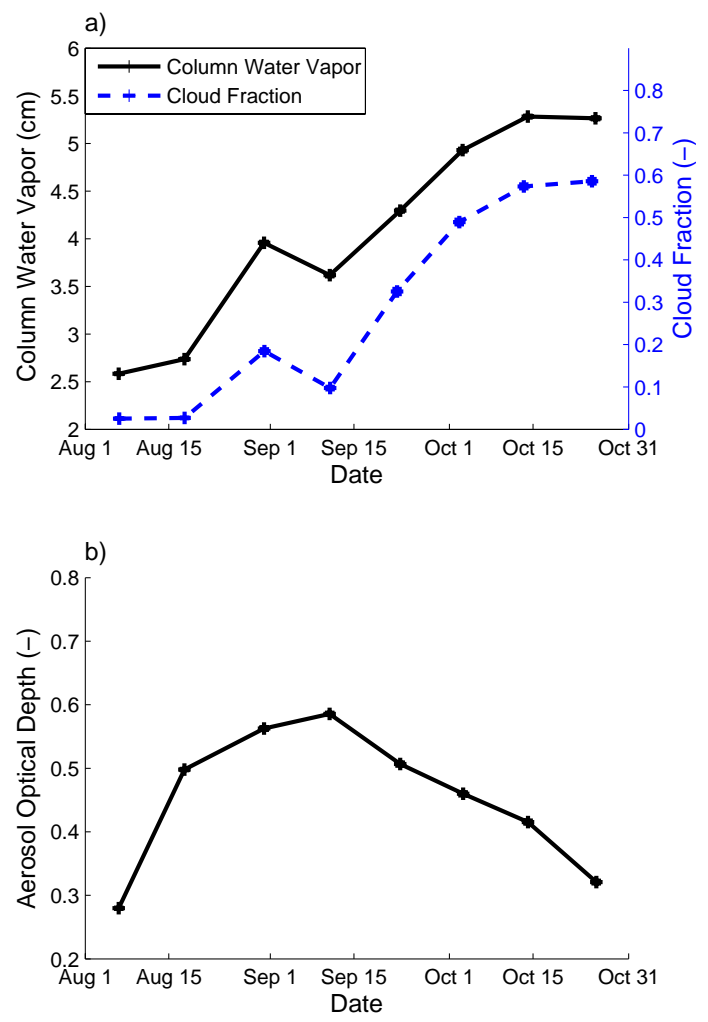

Fig. 3. (a) Column water vapor and warm cloud fraction binned by day of the year for the months of August through October, for the years 2004 through 2007. Data are accumulated into eight bins of equal width between 1 August and 31 October. (b) Aerosol optical depth at $550 \mathrm{~nm}$ binned by day of the year for the same time period as in (a). For (a) and (b), only retrievals with AODs equal to or below 0.8 are included in the time series. Error bars are included but are too narrow to be visible. The number of retrievals included in each bin is provided in Supplement S.1.

CWV and CF in each half season assuming CWV has a controlling influence on $\mathrm{CF}$. If $\mathrm{CWV}$ increases with aerosol in the first half season, then so should CF. If CWV and AOD are negatively correlated in the second half season, then $\mathrm{CF}$ should also be negatively correlated with AOD.

Figure 4a shows CWV binned by AOD for all non-zero CF retrievals in our study region for the same time period as in Fig. 3. The data are stratified by day of the season, with plots representing each half of the season and all days in the season. Figure $4 \mathrm{~b}$ depicts warm CF binned by AOD, for the same periods as in Fig. 4a. In these figures, cloud properties and CWV are binned by AOD, with each bin representing 12.5 percentile of the AOD values. This method has been used previously in other studies so that bias is not introduced through inconsistent sampling in each bin (Lin et al., 2006). The absolute low and high AOD boundaries are assigned to be 0.05 and 0.8 , however, the location of individual bin edges vary for each plot. The bin centers are defined as the average AOD value in each bin and error bars representing the standard errors of the bin average $\left(\sigma / \mathrm{N}^{1 / 2}\right)$ are also included.

In the first half season, 1 August to 15 September, there is a positive correlation between both $\mathrm{CWV}$ and $\mathrm{AOD}$, as well as between CF and AOD, as expected from Fig. 3. However, in the second half season, 15 September to 31 October, CWV is negatively correlated with AOD as expected, but CF is not. This deviation of the CF relationship to AOD in a direct correlation overrides the controlling effect of the seasonal CWV evolution on cloud formation and strongly points to aerosol as a modifying element of cloud properties. We conclude that both large-scale meteorological factors traced by seasonallyvarying CWV and aerosol loading may contribute to changes in warm CF in our region of interest.

This conclusion has important implications for analyzing aerosol-cloud interactions. Following previous studies, common practice would be to accumulate all pixels with both aerosol and cloud retrievals during the biomass burning season, and then bin the cloud retrievals by AOD, implicitly assuming constant meteorological conditions throughout this period (Koren et al., 2004, 2008). However, this study finds that embedded in these correlations are systematic variations in CWV with AOD. As a result, this CWV signal may impact aerosol-cloud correlations. For example, the "boomerang" shape identified by Koren et al. (2008) and attributed to the combination of microphysical and radiative effects by aerosols on clouds may also contain an element of withinseason evolution of the meteorological conditions. In Fig. 4a we identify a boomerang shape in the CWV vs. AOD plot that is due solely to the combination of the different halves of the season, and not a physical consequence of the aerosol at all. The similar boomerang shape in CF over the full biomass season seen in Fig. 4b reflects both the actual relationship between $\mathrm{CF}$ and AOD in the latter half season and also the artifact created by combining the two half seasons.

Figure $4 \mathrm{c}, \mathrm{d}$ show $\mathrm{CWV}$ and $\mathrm{CF}$ again binned by AOD, but only for cloud fractions less than 0.5 . By retaining only low cloud fractions, more of the aerosol layer is exposed to sunlight in each $10-\mathrm{km} \times 10-\mathrm{km}$ retrieval box. Even though lower cloud fractions may lead to increased solar radiation at the surface, and thus more evapotranspiration which could increase CWV, Fig. 4c shows little difference in both the shape of the graph and the magnitude of the change of CWV with AOD when compared with Fig. 4a. This suggests that the lower CF does not have an appreciable effect on the relationship between CWV and AOD. Yet, we do find that the increased solar radiation affects the relationship between aerosol loading and cloud fraction, consistent with Koren et al. (2008). It has been hypothesized that the increased aerosol exposure to sunlight will result in a stronger aerosol absorption effect on clouds and that the decrease of CF with AOD will begin at lower values of aerosol loading (Koren et al., 2008). The less cloudy plot of Fig. $4 d$ has shifted the turning point between increasing and decreasing $\mathrm{CF}$ to lower aerosol loading. Figure $4 \mathrm{~d}$ locates the turning point at $\mathrm{AOD}=0.30-0.40$, as opposed to the total data set of Fig. $4 \mathrm{~b}$ 

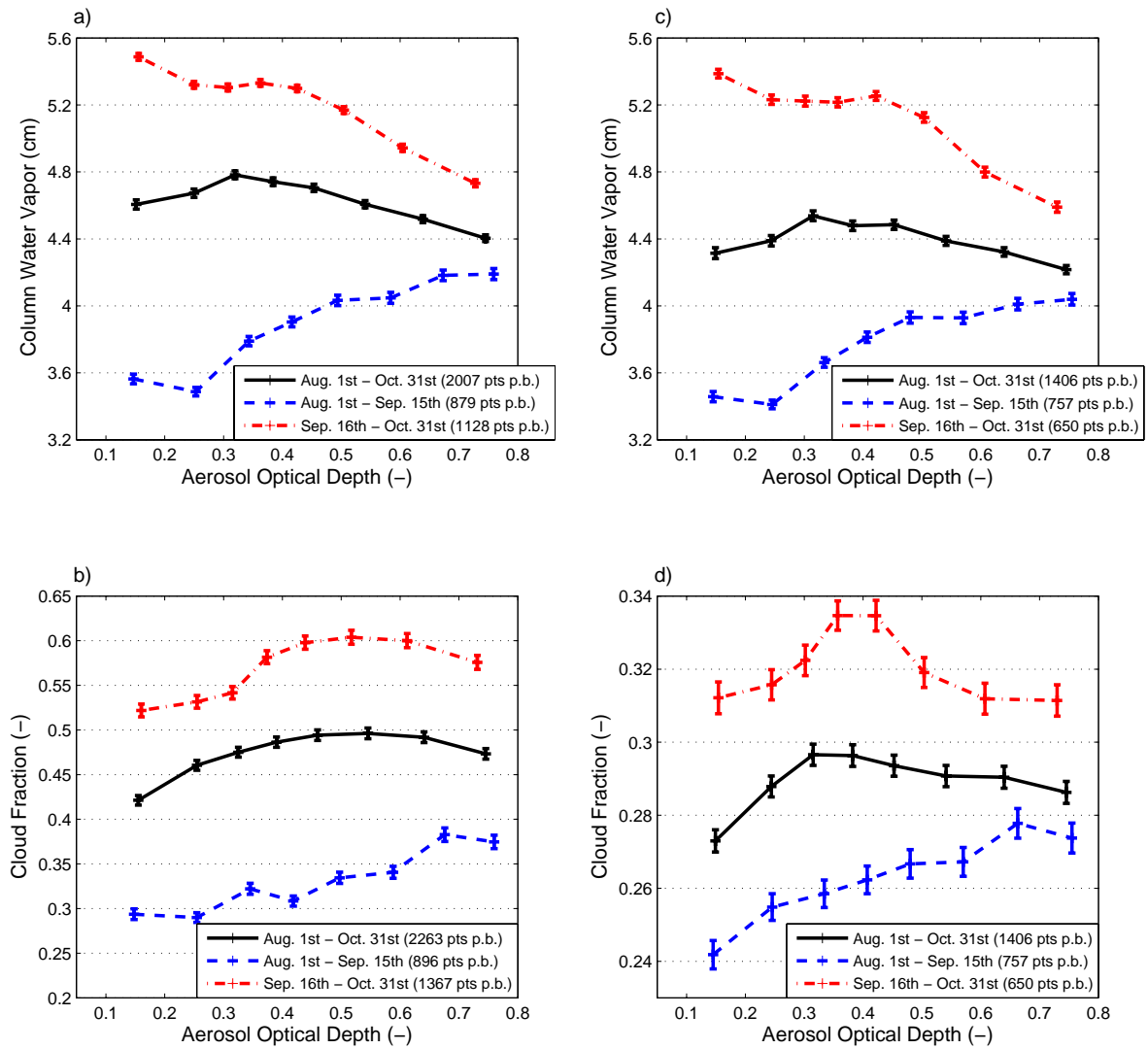

Fig. 4. (a) Column water vapor binned by aerosol optical depth for all co-located warm cloud retrievals for the months of August through October, for the years 2004 through 2007. Error bars denote the standard error in each bin. (b) Cloud fraction binned by aerosol optical depth for all warm cloud retrievals for the same time period as in (a). (c) Column water vapor binned by aerosol optical depth for all co-located warm cloud retrievals with cloud fractions less than 0.5. (d) Cloud fraction binned by aerosol optical depth for all warm cloud retrievals with cloud fractions less than 0.5 . The number of retrievals included each bin is noted in the legend.

where the turning point is at $\mathrm{AOD}=0.55$. The boomerang relationships in Fig. 4a, d exist well outside the standard errors of the individual bins, a result which supports their statistical significance.

Figures 3 and 4 both confirm the associations between clouds and aerosols identified from satellite retrievals observed in previous studies and also sound a warning that some of these associations contain an artifact introduced from slowly evolving meteorological factors that can be traced by CWV. We note a difference between this study and the previous studies mentioned above. We are focusing on a very small $\left(5^{\circ} \times 5^{\circ}\right)$ region in Rondônia, compared to previous studies, which took a broader view that included the entire Amazon Basin with its varied surface types, biomes and climatic zones. The relationships shown in Fig. 3 are applicable for larger areas as well, but the range between low and high CWV and low and high AOD over the season becomes diluted as the study area is expanded. Our study area captures the strong seasonal variation in water vapor, cloud, and aerosol properties that still exists but in diluted magnitudes when our region is combined with surrounding areas.
We can identify the transition between meteorological seasons by using CWV as a tracer for the slow onset of the rainy season and stratify the data set using this parameter to control for meteorology. Figure 5a depicts CWV binned by AOD for all CF retrievals, and for five groupings of CWV. Each grouping spans 16 percentile points, with a minimum percentile of $10 \%$ and a maximum percentile of $90 \%$ to avoid extreme values. These bounding low and high percentiles refer to CWV values of $2.10 \mathrm{~cm}$ and $5.33 \mathrm{~cm}$, respectively. In general, lower percentiles represent retrievals earlier in the season whereas higher percentiles represent retrievals later in the season. The number of retrievals per bin increases with CWV due to decreasing prevalence of cloud-free pixels between the beginning and end of the biomass burning season. Figure 5a illustrates that while the range of CWV represented by each grouping is $0.65 \mathrm{~cm}$ on average, CWV only varies marginally between AOD bins, with a maximum difference of $0.10 \mathrm{~cm}$ between any two bins in any grouping. This nominal variation in CWV within each grouping is likely to have only a minimal effect on cloud properties. 

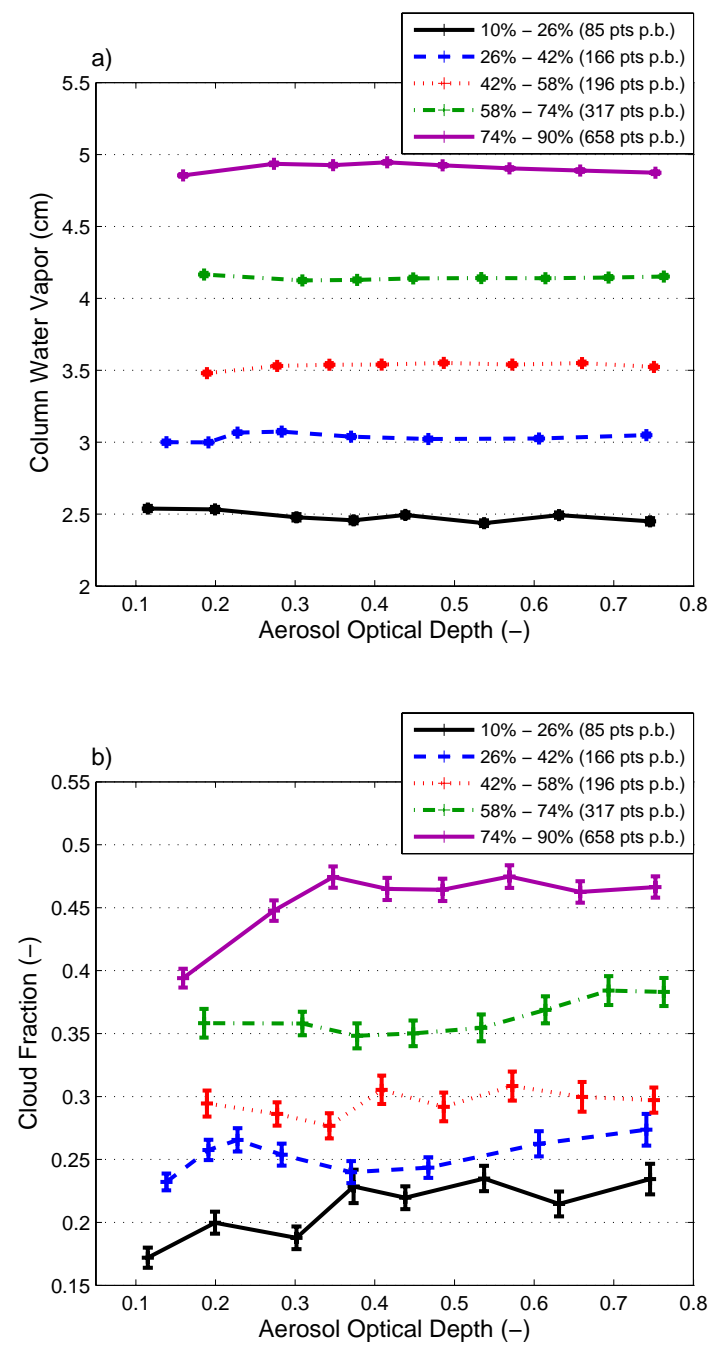

Fig. 5. (a) Column water vapor and (b) cloud fraction binned by aerosol optical depth for all co-located warm cloud retrievals, stratified by different percentile groupings of column water vapor. Data represent the months of August through October, for the years 2004 through 2007. The number of retrievals included each bin is noted in the legend.

Figure 5b depicts CF binned by AOD for the five CWV groupings. The change in $\mathrm{CF}$ with $\mathrm{AOD}$ in Fig. $5 \mathrm{~b}$ is more representative of the true aerosol effect on $\mathrm{CF}$ compared to Fig. 4 since the influence of varying CWV has been minimized. CF increases with CWV, as indicated in Fig. 3a. For each CWV grouping, $\mathrm{CF}$ either increases with $\mathrm{AOD}$, on average, across the AOD range between 0.05 and 0.8 , or remains relatively constant along this range. The 42 nd to 58 th percentile grouping and the 58th to 74th percentile groupings do not exhibit an increase to the extent of the other groupings. It is probable that increasing $\mathrm{CF}$ with $\mathrm{AOD}$ is absent in these middle CWV groupings due to the lack of low AODs during the mid-season peak of the biomass burning season. In this figure, the aerosol effect on CF does not appear to
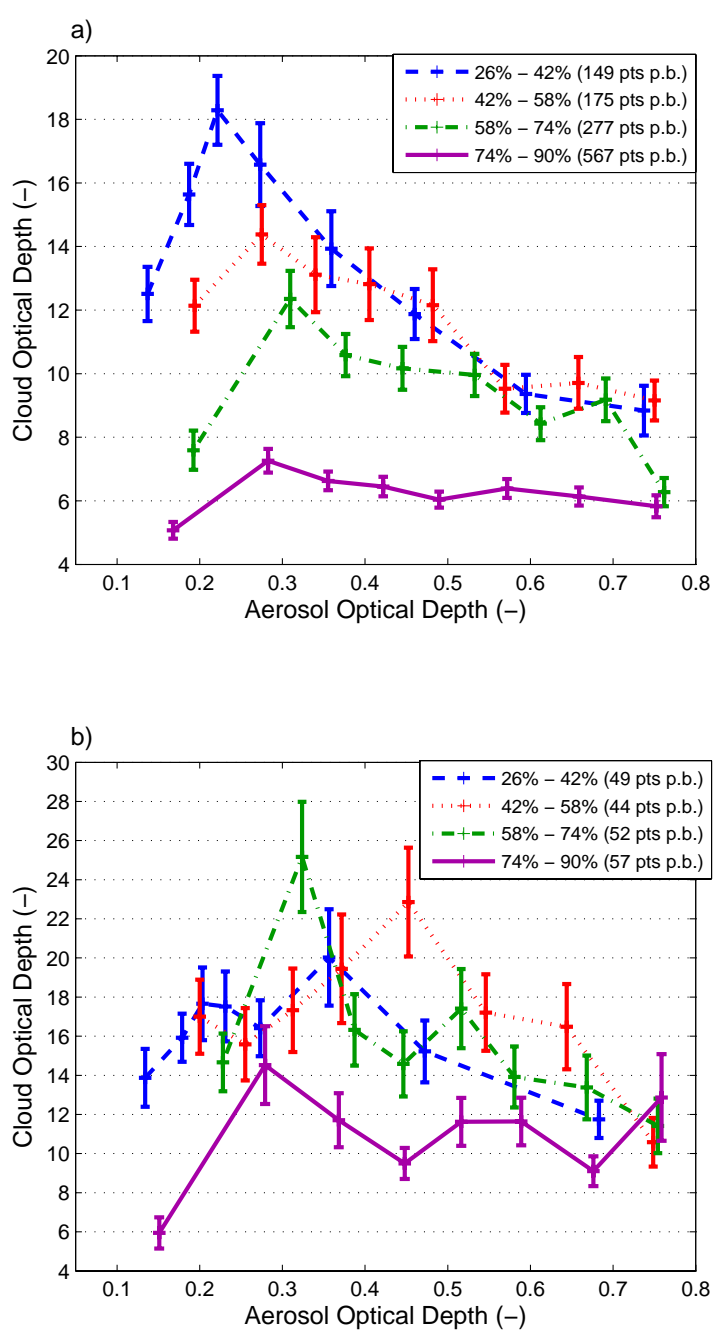

Fig. 6. (a) Liquid cloud optical depth binned by aerosol optical depth for all warm cloud retrievals, stratified by different percentile groupings of column water vapor. Data represent the months of August through October, for the years 2004 through 2007. (b) Same as (a) but only for retrievals with cloud top pressures between $800 \mathrm{hPa}$ and $850 \mathrm{hPa}$. The number of retrievals included each bin is noted in the legend.

be largely dependent on CWV, which agrees with previous studies (Feingold et al., 2001).

The highest CWV grouping appears to demonstrate the greatest microphysical effect: $\mathrm{CF}$ increases at the greatest rate below an AOD of 0.35 compared to other groupings. In high water vapor loading environments, addition of aerosol at low AODs may increase $\mathrm{CF}$ to a greater extent than in lower water vapor loading environments, as also suggested in Yu et al. (2007). This result also agrees with the aerosol absorption cloud fraction feedback - the greater the initial CF, the greater the microphysical effect (Koren et al., 2008).

The flattening of these curves at higher AODs suggests a saturation of the microphysical effect. The absence of 
a strong aerosol absorption effect in Fig. 5b conflicts with some studies (Koren et al., 2004, 2008), but agrees with others depending on the year analyzed (Lin et al., 2006; Yu et al., 2007). Part of the discrepancy may be due to the gradient of aerosol absorption properties north to south. The focus area of this study is embedded in the deforestation zone, with smoke having higher single scattering albedo (less absorption) than the smoke in the Cerrado to the south (Dubovik et al., 2002). A less absorbing smoke will have less radiative effect than the model formulated by Koren et al. (2008). Yet, our results indicate that variation in water vapor loading may have inadvertently affected previous analyses of aerosol-cloud interactions over the Amazon.

Aerosol microphysical and radiative effects may also be observed in the cloud optical depth (COD) in addition to the cloud fraction. Figure 6a shows COD binned by AOD for the four highest CWV groupings in Fig. 5. According to the aerosol first indirect effect, increases in aerosol number loading increase the number concentration of cloud condensation nuclei, which in turn increase cloud reflectivity (Twomey, 1977). This effect would be observed as an increase in COD with increasing AOD in Fig. 6a. However, Fig. 6a illustrates that for all four CWV groupings, COD increases only to a certain AOD threshold between 0.2 and 0.35 , and then decreases with increasing AOD. Note that Fig. 6a includes clouds at all stages of vertical development, as long as the clouds are in the liquid phase. While CF in Fig. 5 is highest for the highest CWV grouping and lowest for the lowest CWV grouping, COD behaves oppositely as clouds on average become thinner but cover a larger spatial area at higher CWVs later in the biomass burning season.

Figure $6 \mathrm{~b}$ also shows COD binned by AOD, but only for pixels with average cloud top pressures between $800 \mathrm{hPa}$ and $850 \mathrm{hPa}$. This range is roughly between the median and mean liquid water cloud top pressures over the 2004 to 2007 period. Figure $6 \mathrm{~b}$ shows a similar boomerang pattern of COD versus AOD as Fig. 6a, except with more variation due to a significantly smaller sampling size. Only a narrow range of cloud top pressures are retained to ensure that the COD versus AOD relationships observed in Fig. 6a are not merely the result of sampling clouds at different stages of growth. The AOD turning point of the boomerang in Fig. $6 \mathrm{~b}$ occurs at generally higher AODs than in Fig. 6a, specifically for the lower two CWV groupings. In addition, the magnitude of the decrease in COD with increasing AOD in terms of percentage reduction from the peak is more similar among CWV groupings than in Fig. 6a. This similar COD reduction with AOD among CWV groupings may be because all clouds have similar cloud top pressures and are situated in more homogenous cloud fields.

The increase in COD with AOD for low aerosol loading may be explained by Twomey (1977) and follows from aerosol particles affecting the microphysics of the clouds. The decrease in COD with increasing AOD above AODs of $\sim 0.3$ in Fig. $6 \mathrm{a}$ can be explained by a combination of physical processes and satellite retrieval artifacts. Physically, aerosol absorption of solar radiation can evaporate or thin clouds optically. However, satellite retrieval artifacts can also play a role. Carbonaceous aerosols within or above clouds (Kaufman and Nakajima, 1993), or subpixel holes in the clouds that reveal a dark surface beneath reduces the visible reflectance received by the satellite, and this is interpreted by the retrieval as a lower COD. In fact, a physical-artificial feedback can be started in which the aerosol begins to thin the cloud via radiative processes, revealing more holes that introduce darker visible reflectance to the satellite measurements. The microphysical effect dominates at lower AODs whereas the physical and artificial effects that decrease COD with aerosol loading are radiative in nature and will dominate at higher AODs. Considering that all of the aforementioned explanations for COD decrease are dependent on aerosol radiative absorption, the strength of the COD decrease should be inversely proportional to $\mathrm{CF}$, because lower $\mathrm{CF}$ allows the aerosol greater exposure to sunlight. When the aerosol is exposed to sunlight, more aerosol translates to even higher rates of absorption and heating. The highest magnitude COD decrease occurs for the lowest CWV grouping with the lowest $\mathrm{CF}$, and the lowest magnitude COD decrease occurs for the highest CWV grouping with the highest CF. This pattern is consistent with the hypothesis that the COD decrease is a radiative effect of the aerosols, whether the effect is physical or artificial or a combination of both. It appears unlikely that absorption by water vapor plays a substantial role in Fig. 6 since the largest decrease (largest absorption effect) occurs for the lowest CWV grouping and the smallest decrease (smallest absorption effect) occurs for the highest CWV grouping.

Sorting out the exact cause of the COD decrease with increasing AOD is difficult. The absence of a strong absorption effect in the CF plots would suggest that darkening plays a role in the COD plots. Wilcox et al. (2009) found that biomass burning aerosols over a stratocumulus deck will artificially reduce cloud optical depths retrieved by the MODIS sensor. The darkening bias was found to be greater for higher AODs, as expected, and also for higher values of COD. Both of these relationships are observed in Fig. 6a. Unlike the Wilcox et al. (2009) study, the data in Fig. 6 do not consist only of scenarios with aerosols above clouds. Analysis of an individual day using both MODIS and the CALIPSO lidar, the latter of which has an overpass time roughly $1 \mathrm{~min}$ after the Aqua satellite and can detect the vertical distribution of clouds and aerosols, results in a similar boomerang relationship between COD and AOD even when the cloud layer forms at or above the top of the aerosol layer. Figure 7 shows the results of just one day, 12 August 2006, where clouds form above the aerosol layer and COD exhibits a boomerang shape with AOD. Figure 7 a shows the CALIPSO vertical feature classification excluding data below a medium confidence level, and Fig. $7 \mathrm{~b}$ shows COD binned by AOD from the MODIS Aqua sensor on this same day. A third degree polynomial function that best fits the data 
is also plotted, illustrating that COD increases with increasing AOD initially, but then decreases with increasing AOD at higher values of AOD, similar to Fig. 6 a.

Kaufman and Nakajima (1993) also hypothesized that biomass burning aerosol darkens Amazonian clouds due to the presence of black carbon inside clouds. This study found that cloud reflectance at $640 \mathrm{~nm}$ is reduced from 0.71 to 0.68 for an increase in aerosol optical depth between 0.1 and 2.0. This small decrease in visible reflectance is likely not the sole cause of decreases in COD between $20 \%$ and $50 \%$, observed in Fig. 6a. Because of the modest role expected by the darkening of the clouds and the absence of a strong absorption effect in the CF plots, the physical-artificial feedback involving thinning clouds and increasing inclusion of dark reflectance from the surface beneath is the most promising explanation. Yet, modeling studies have found that black carbon absorption in clouds results in a non-negligible feedback to surface and mid-tropospheric temperatures globally (Jacobson, 2006). This in-cloud absorption may constitute up to $10 \%$ or more of the total temperature feedback from black carbon. As a result, aerosol absorption in clouds may have a large effect on the radiative balance of the atmosphere in the Amazon region.

\subsection{Effect of land cover on aerosol-cloud interactions}

Biomass burning in the Amazon influences clouds in two ways - through smoke effects and through land use changes. Smoke particles can change cloud microphysics and heat the atmospheric cloud environment by absorbing sunlight, as described above. Land use changes that convert forest to pasture and cropland modify net radiation at the surface through albedo changes and by altering surface heat and water vapor fluxes. These changes can in turn affect cloud development. By dividing our data set into forested and deforested (pasture) subsets, we can begin to understand the relative effects of aerosols and land use changes on cloud properties, and especially how land use changes modify aerosol effects.

To ensure that cloud/aerosol/atmospheric properties can be separated between forest and pasture, we use NCEP NCAR Reanalysis data at $700 \mathrm{mb}$ to estimate advection of clouds/aerosols/atmospheric properties on the diurnal scale $(\sim 6 \mathrm{~h})$. We find a spatially- and temporally-averaged wind speed over our study region and study period of $6.50 \mathrm{~m} \mathrm{~s}^{-1}$ with a standard deviation of $0.56 \mathrm{~m} \mathrm{~s}^{-1}$ over the years between 2004 and 2007. Thus, on average, clouds/aerosols will advect $\sim 140 \pm 12 \mathrm{~km}$ assuming a diurnal time scale. Since the forested and pasture regions employed in the study are hundreds of kilometers in length and width, it is likely that clouds/aerosols will remain over the same land surface over this time frame. On even shorter time intervals, such as the time scale of shallow cumulus clouds ( $\sim 30 \mathrm{~min})$, clouds/aerosols will rarely move between land surface types.

Table 1 shows average values of cloud, aerosol, and atmospheric profile parameters retrieved from the Level 2 MODIS
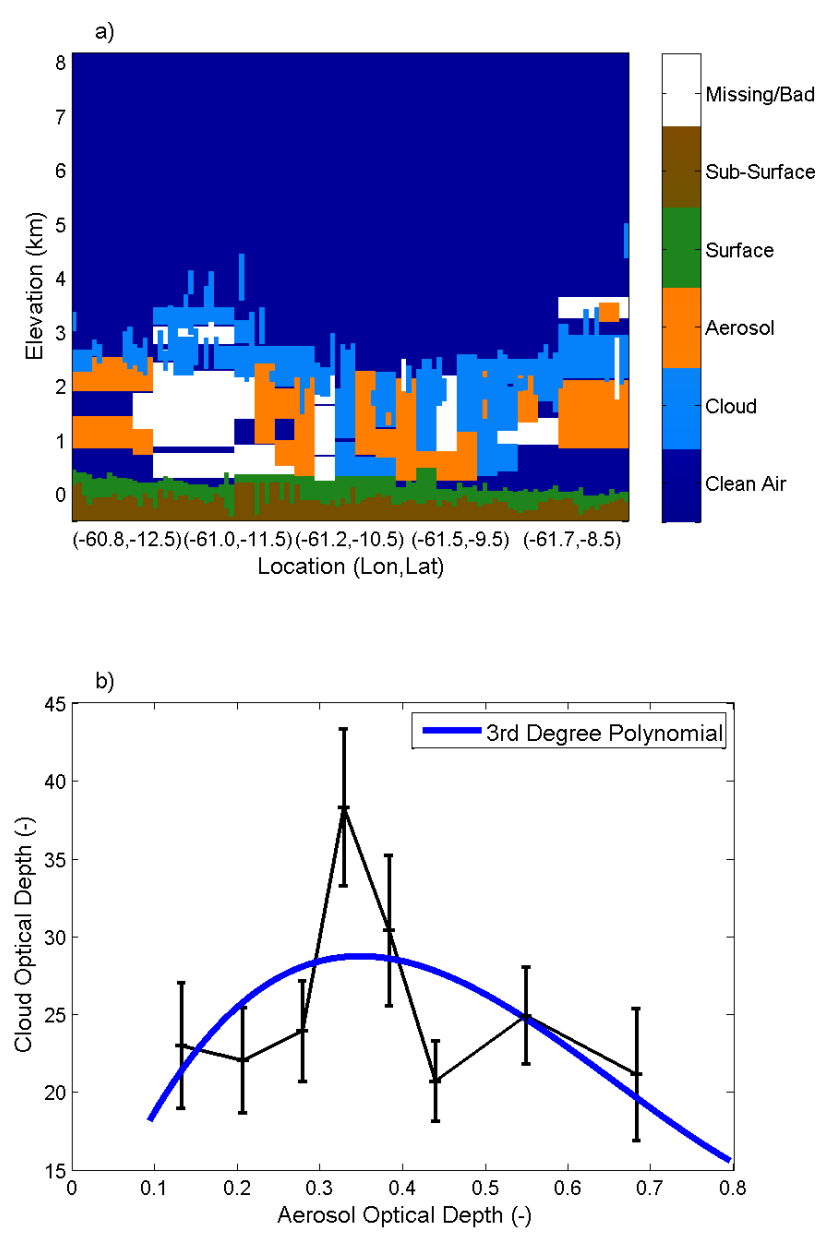

Fig. 7. (a) Vertical Feature Mask from the CALIPSO lidar on a path through the study region for a single day during the study period, 12 August 2006. On this day, clouds mostly form near the top of the aerosol layer. Clouds that extend throughout the column could be misclassified heavy aerosol plumes, however, we use only medium to high quality data to minimize misclassification. (b) Liquid cloud optical depth binned by aerosol optical depth on the same day as in (a), throughout the $5^{\circ} \times 5^{\circ}$ study region for cloud top pressures between the 5 th and 50th percentiles $(784 \mathrm{mb}-845 \mathrm{mb}$ ). The 5th percentile refers to the height of the highest $5 \%$ of warm clouds and the 50th percentile is the median height of warm clouds. Low clouds likely embedded within the aerosol layer are removed ( $>50$ th percentile) in addition to high clouds which may be above the influence of aerosols ( $<5$ th percentile), leaving 167 retrievals for analysis $(\sim 21$ retrievals per bin). A least squares third-degree polynomial that best fits the pre-binned data is also plotted.

products for both forest and pasture. Frequency distributions as well as a measure of statistical significance for each parameter in Table 1 can be found in Supplement S.2. Table 1 shows that average warm cloud fraction is higher for the pasture compared to the forest, which agrees with previous studies (Cutrim et al., 1995; Negri et al., 2004; Wang et al., 2009). In addition, a greater average cloud top pressure 
is observed for the pasture, which suggests more shallow cloud development over the pasture compared to the forest (Wang et al., 2000, 2009; Durieux et al., 2003; Chagnon et al., 2004). CWV is also higher over the forest, presumably due to the reduction in evapotranspiration over the pasture compared to the forest (Nobre et al., 1991; Correia et al., 2007). The shorter roughness length and lower specific heat of the pasture result in greater surface heating, as supported by the higher $1000 \mathrm{hPa}$ temperature over the pasture compared to the forest. Greater surface heating also results in a lower atmospheric low-level stability over the pasture, defined as the temperature at $850 \mathrm{hPa}$ minus the temperature at $1000 \mathrm{hPa}$ (Polcher and Laval, 1994; Correia et al., 2007). Average AOD is similar between the two land cover types, a finding which is anticipated since aerosol concentrations are often spatially homogeneous, particularly at some distance away from concentrated smoke plumes.

Comparison of aerosol effects on CWV and clouds between different land cover types requires careful consideration of consistent sampling procedures. To perform this analysis, the same number of samples must be retrieved between forest and pasture for a given day for each AOD bin to ensure that weighting of the data by time of the year is consistent between both land cover types. The sampling process is as follows: first, for each parameter and each AOD bin, the number of samples for each day is determined for forest and pasture. For the land cover type (forested or pasture) with the minimum number of samples, the same number of samples is taken from the other land cover type. Because bin edges must be assigned beforehand using this procedure, the number of samples in each AOD bin is not consistent among all bins. The eight bins for both forest and pasture are equally spaced between 0.05 and 0.8 .

Several randomized mixed forest and pasture subsamples are also conducted to assess the significance of the segregated land cover analysis. In each random subsample, the retrievals are randomly sampled between forest and pasture according to the relative proportion of forest and pasture retrievals in the actual data. This method results in no systematic segregation by land cover in each randomized subsample. Again, the data are processed such that the same number of samples is retained between forest and pasture for a given day for each AOD bin. Figure 8a illustrates the difference in the average sampled day of the year between pasture and forest in each AOD bin for both the actual data and the randomized subsamples. The difference is zero for all bins, indicating that the sampling procedure by definition does not weight the result by day of the year, thus there is no difference in the large-scale meteorology between the pasture and forest for each AOD bin.

One of the primary underlying assumptions in this study is that aerosols do not impact CWV through changes in evaporation and transpiration, but instead that $\mathrm{CWV}$ is an indicator of the synoptic-scale meteorology. Aerosols could, in theory, affect evapotranspiration rates by changing both the magni-
Table 1. Average warm cloud, aerosol, and atmospheric profile statistics for both forested and deforested land in our study region. The averaging period is for August through October for the years 2004 through 2007.

\begin{tabular}{lrr}
\hline & Forested & Deforested \\
\hline Cloud Fraction $(-)$ & 0.52 & 0.63 \\
Cloud Optical Depth $(-)$ & 9.18 & 8.28 \\
Cloud Top Pressure $(\mathrm{hPa})$ & 796.2 & 817.8 \\
Cloud Effective Radius $(\mu \mathrm{m})$ & 15.8 & 14.6 \\
Cloud Water Path $\left(\mathrm{g} \mathrm{m}^{-2}\right)$ & 82.8 & 69.4 \\
Column Water Vapor $(\mathrm{cm})$ & 3.76 & 3.54 \\
$850 \mathrm{hPa}$ Temperature $(\mathrm{K})$ & 292.6 & 293.0 \\
1000 hPa Temperature $(\mathrm{K})$ & 307.2 & 311.4 \\
Low-Level Stability & -14.6 & -18.4 \\
{$[$ Temperature $850 \mathrm{hPa}$ minus } & & \\
Temperature $1000 \mathrm{hPa}(\mathrm{K})]$ & & \\
AOD at 550 nm $(-)$ & 0.92 & 0.89 \\
\hline
\end{tabular}

tude and diffuse fractionation of radiation reaching the surface (Roderick et al., 2001; Jacobson, 2002; Yu et al., 2002; Knohl and Baldocchi, 2008). Because deforested land has a leaf area index several times lower than forested land in addition to a significantly lower heat capacity, aerosols could affect the evapotranspiration and evaporation from the ground differently between forest and pasture. We test this assumption by analyzing aerosol-CWV relationships separately over the forested and deforested regions. Table 1 indicates that the forest CWV is $0.22 \mathrm{~cm}$ higher on average than the pasture during our study period, which we assume is the result of differences in evapotranspiration. If we observe this difference correlated with aerosol, then we may suspect that aerosol is modifying the CWV and our assumption of using CWV as a tracer for the large-scale meteorology in the former portion of the paper may be incorrect.

Figure $8 \mathrm{~b}$ shows $\mathrm{CWV}$ binned by AOD over the pasture minus CWV binned by AOD over the forest for retrievals with non-zero cloud fractions. Error bars represent the square root of the sum of the pasture and forest standard errors squared. There is a lack of a significant increasing or decreasing relationship between CWV differences and AOD. Instead, CWV is slightly higher over the forest compared to the deforested land for all AOD bins, an offset owed to the difference in evapotranspiration between pasture and forest. The random subsamples show no such offset since forest and pasture retrievals are randomly mixed. Figure $8 \mathrm{~b}$ illustrates that the addition of aerosols below an AOD of 0.8 most likely does not influence evapotranspiration sufficiently to affect CWV differently between pasture and forest. The little variation that does exist between AOD bins is well within the standard error. This observation is supported by modeling studies that suggest absorbing aerosol reduces sensible heat flux more so than latent heat flux over land (Yu et al., 2002; 

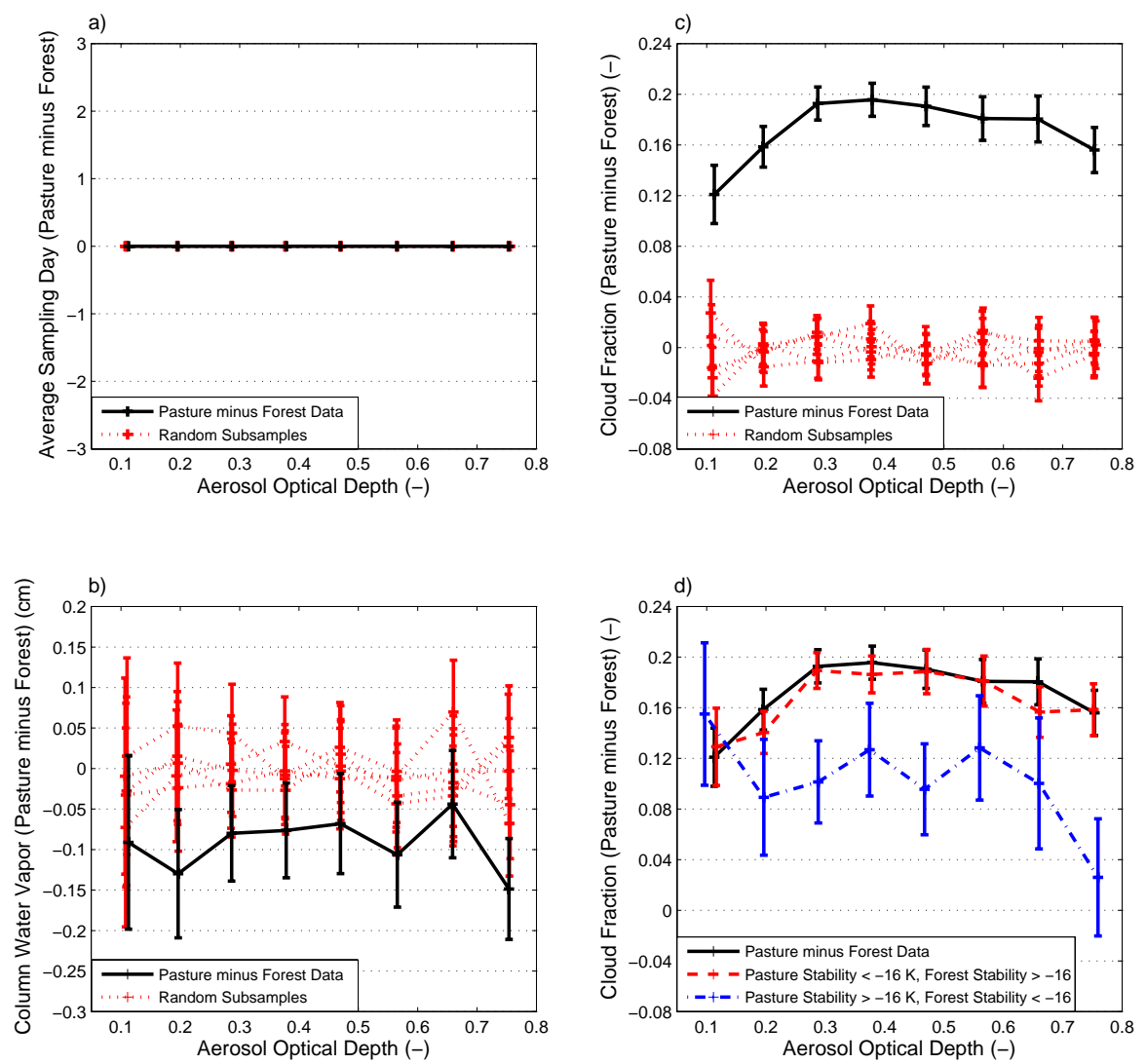

Fig. 8. (a) Difference between the average sampled day of the year in each AOD bin for the pasture and forest sites. (a), (b) and (c), dotted red lines represent the results of five random subsamples, where retrievals over forest and pasture are mixed. Data represent the months of August through October, for the years 2004 through 2007. (b) Differenced column water vapor binned by AOD between pasture and forest land cover types. (c) Differenced cloud fraction binned by AOD between pasture and forest land cover types. (d) Solid black line: same as (c), dashed red and dash-dotted blue lines: differenced cloud fraction binned by AOD stratified by low-level stability, defined as the temperature at $850 \mathrm{hPa}$ minus the temperature at $1000 \mathrm{hPa}$. The stratification values are different between pasture and forest for each stratification case. The number of retrievals included in each bin is provided in Supplement S.3.

Matsui et al., 2008). More generally, the addition of aerosol below an AOD of 0.8 does not have a noticeable impact on CWV. Thus, changes in CWV may be attributed largely to changes in synoptic-scale conditions and seasonal cycles.

Figure 8c shows CF binned by AOD over the pasture minus CF binned by AOD over the forest. Absolute values of aerosol-cloud correlations over pasture and forest are not computed as they will be influenced by variations in CWV, similar to Fig. 4. However, because the same number of retrievals is retained over the pasture and forest for each day in each AOD bin, computing CF differences between pasture and forest in each AOD bin will remove influences of the larger-scale meteorology. The CF difference between pasture and forest is always positive in Fig. 8c, indicating that $\mathrm{CF}$ is greater over the pasture than the forest, as also shown in Table 1. The figure also illustrates that there are increasingly more clouds over the pasture with increasing AOD, up to an AOD of $\sim 0.4$. After this AOD threshold, the plot flattens and even reverses slightly. The five random subsamples do not show higher average cloud fractions over the pasture compared to the forest, nor do they show a stronger microphysical aerosol forcing over the pasture, strengthening the significance of these results. What causes this noticeable dissimilarity in the aerosol effect between pasture and forest at AODs below 0.4 ? Because differences in CWV are likely not a driving factor due to the results of Fig. 8b, it is suggested that differences in low-level atmospheric stability may be at the root of the dissimilarity.

Figure $8 \mathrm{~d}$ again shows the difference in $\mathrm{CF}$ binned by AOD between the pasture and forest similar to Fig. 8c, but also shows the CF difference stratified by low-level stability derived from MODIS temperature products. The first case (dashed red line) includes all retrievals where the low-level stability is less than $-16 \mathrm{~K}$ over the pasture and greater than $-16 \mathrm{~K}$ over the forest and the second case (dash-dotted blue line) includes all retrievals where the low-level stability is greater than $-16 \mathrm{~K}$ over the pasture and less than $-16 \mathrm{~K}$ over the forest. A threshold stability value of $-16 \mathrm{~K}$ is selected 
because it is very close to the median stability over both pasture and forest. In addition, a temperature difference of $16 \mathrm{~K}$ or greater between 850 and $1000 \mathrm{hPa}$ conservatively corresponds to an absolutely unstable atmosphere, according to a tropical standard atmosphere.

The dashed red line represents the difference in $\mathrm{CF}$ between pasture and forest only for retrievals where the pasture is considered unstable and the forest is considered relatively more stable. In this scenario, the difference in CF between pasture and forest responds similarly to increasing AOD as the plot that includes all stabilities (solid black line). This similarity is expected since the pasture is often more unstable than the forest (Supplement S.2), which is likely due to the lower specific heat of the pasture compared to the forest. The dash-dotted blue line represents the reverse scenario, retrievals where the forest is considered unstable and the pasture relatively more stable. We cannot determine with certainty what causes this scenario from observations alone, however, it could be related to local effects such as the presence/thickness of clouds, inland breeze mesoscale circulations, or differences in surface reflectivity due to albedo differences between forest and pasture. Because this scenario is considerably less likely, larger standard errors are observed. Unlike the first scenario (dashed red line) that shows increasingly higher cloud fractions with increasing AOD over the pasture compared to the forest, this reverse scenario (dashdotted blue line) does not exhibit such a pattern. The absence of an increasing relationship between CF and AOD in this reverse scenario may be attributed to the higher stability over the pasture compared to the forest - the microphysical forcing of clouds may be weaker in atmospheres that lack sufficient low-level instability. These results are consistent with findings in Yu et al. (2007).

Low-level stability appears to be a factor or a tracer for how aerosol modifies cloud fraction differently over forested and deforested surfaces. The greater instability that generally occurs over deforested land appears to encourage increases in CF with AOD. The statistical approach used here is limited, and cannot characterize the full mesoscale circulations thought to be responsible for the general differences in CF between forested and deforested surfaces (Wang et al., 2009). A proper 3-D cloud resolving model with adequate similations of surface fluxes and mesoscale circulations will be needed to explain the associations identified in Fig. 8d.

\section{Conclusions}

In this study, a $5^{\circ} \mathrm{NS} \times 5^{\circ} \mathrm{WE}$ region over Rondônia, Brazil was analyzed using relatively high resolution aerosol, cloud, water vapor, and atmospheric temperature profile data from the Moderate Resolution Imaging Spectroradiometer (MODIS). Four years of data (2004-2007) during the biomass burning transition season (August-October) were compiled to analyze the effect of aerosols on warm cloud development. Several years of data were employed to gather a large enough dataset for analysis, and to smooth out interannual variability. MODIS observations illustrate that column water vapor (CWV) generally increased throughout the biomass burning season, while aerosol optical depth (AOD) peaked during the middle of the season. These within-season relationships between CWV and AOD may produce false correlations in cloud parameter versus AOD plots when all data throughout the biomass burning season are accumulated and analyzed together. By dividing the total period into subperiods, we found evidence that both large-scale meteorological factors traced by CWV and aerosol loading contributed to modification of the cloud fraction (CF) in our area of interest. To better account for this meteorological variability, data were stratified by CWV. When background CWV variability was removed, CF either increased or remained constant with AOD, depending on the CWV stratification. The largest increase in $\mathrm{CF}$ with AOD occurred at the highest value of CWV.

Decrease of CF with AOD, attributed to aerosol absorption effects, was not observed in the CF versus AOD plots once the data were stratified by CWV. However, the decrease was observed in the data divided into seasonal subsets, and associations between CF and AOD were consistent with expectations that follow from the aerosol-cloud fraction feedback hypothesized by Koren et al. (2008). At lower cloud fractions when the aerosol has greater exposure to sunlight, the decrease of cloud fraction which we attributed to aerosol absorption effects increased in magnitude and was shifted to lower values of AOD.

Relationships between cloud optical depth (COD) and aerosol loading are more difficult to interpret. Plots of COD against AOD showed an initial increase of cloud optical depth, and then a turning point where clouds appeared to become optically thinner as aerosol loading increased. Increasing COD with aerosol may be attributed physically to the processes described by Twomey (1977), but the decrease of COD with AOD is best described by a combination of physical processes and satellite retrieval artifacts. Absorbing aerosol may cause cloud droplets to evaporate and clouds to thin. This is a legitimate physical process. On the other hand, dark aerosol in and above the clouds may also decrease the cloud reflectance observed by the satellite, which the satellite retrieval interprets as a decrease in COD. As the clouds thin, subpixel holes in the clouds open, allowing darker reflectance from the surface beneath to again darken the cloud reflectance measured by the satellite. Again the cloud reflectance is artificially too low, resulting in COD retrievals that are too low, which contributes to the strong decrease of COD with AOD observed in the data analysis. Assuming that the relationship between decreasing COD and increasing AOD is due to both radiative effects as well as retrieval artifacts, our results suggest that global climate models that do not include treatment of aerosol absorption in and around clouds are inaccurate over regions with high concentrations of absorbing aerosol. 
This study also addressed the effect of aerosols on CWV and clouds over different land cover types. Land cover was segregated into forested and deforested surfaces using the MODIS land cover product, and the response of CWV to increasing AOD was analyzed between the forested and deforested land. We found that aerosols likely do not have a noticeable effect on CWV. Thus, it may be assumed that temporal changes in CWV are largely a function of the synopticscale meteorology and that aerosol is completely independent of CWV at the local level. The independence of CWV and AOD is an inherent assumption in the former portion of the paper, supported by the analysis in the latter portion of the paper.

This study showed that the relationship between $\mathrm{CF}$ and AOD is quite sensitive to land cover type. Microphysical effects appeared to be stronger over the deforested land compared to the forested land, increasing CF with increasing AOD to a greater extent over the deforested land compared to the forest. The difference in the aerosol microphysical effect over the contrasting land cover types appears to be linked to the differing lower tropospheric stability over these two surfaces, but a full understanding of the complex interaction between aerosols, clouds, and land surface types cannot be achieved from the statistical approach used here. A 3-D cloud resolving model with adequate representation of surface-atmosphere exchange and the ability to similate mesoscale circulations and cloud microphysical processes will be required.

The relationships shown here cannot, with certainty, be extrapolated to different times of the year or different regions of the world. These aerosol-cloud correlations are largely dependent on the physical and optical characteristics of the biomass burning aerosol (i.e. size distribution, composition); therefore, a different aerosol mixture may or may not have a different impact on clouds. However, a similar analysis to this one over other biomass burning regions or heavily fossilfuel polluted regions would be helpful in determining if these relationships could be extended more generally. More importantly, modeling-based studies are required to assign causation to the correlations found here.

\section{Supplementary material related to this article is available online at: http://www.atmos-chem-phys.net/11/3021/2011/ acp-11-3021-2011-supplement.pdf.}

Acknowledgements. This study was supported by NASA under Grant No. NN07AN25G and by the EPA under Agreement R833371, as well as by the NASA Earth Systems Science Fellowship and the Stanford Graduate Fellowship. We are grateful to James Coakley, Steven Platnick, and Rich Kleidman for helpful comments. We also thank Brent Holben and his staff for establishing and maintaining the two AERONET sites used in this investigation, Abracos Hill and Ji Paraná SE.

Edited by: T. J. Dunkerton

\section{References}

Ackerman, A. S., Toon, O. B., Stevens, D. E., Heymsfield, A. J., Ramanathan, V., and Welton, E. J.: Reduction of tropical cloudiness by soot, Science, 288, 1042-1047, 2000.

Albrecht, B. A.: Aerosols, cloud microphysics, and fractional cloudiness, Science, 245, 1227-1230, 1989.

Andreae, M. O., Artaxo, P., Brandão, C., Carswell, F. E., Ciccioli, P., da Costa, A. L., Culf, A. D., Esteves, J. L., Gash, J. H. C., Grace, J., Kabat, P., Lelieveld, J., Malhi, Y., Manzi, A. O., Meixner, F. X., Nobre, A. D., Nobre, C., Ruivo, M d. L. P., Silva-Dias, M. A., Stefani, P., Valentini, R., von Jouanne, J., and Waterloo, M. J.: Biogeochemical cycling of carbon, water, energy, trace gases, and aerosols in Amazonia: The LBAEUSTACH experiments, J. Geophys. Res., 107(D20), 8066, doi:10.1029/2001JD000524, 2002.

Andreae, M. O., Rosenfeld, D., Artaxo, P., Costa, A. A., Frank, G. P., Longo, K. M., and Silva-Dias, M. A. F.: Smoking rain clouds over the Amazon, Science, 303, 1337-1342, 2004.

Brennan, J. I., Kaufman, Y. J., Koren, I., and Li, R.-R: Aerosolcloud interaction - misclassification of MODIS clouds in heavy aerosol, IEEE T. Geosci. Remote, 43(4), 911-915, 2005.

Chagnon, F. J. F., Bras, R. L., and Wang, J.: Climatic shift in patterns of shallow clouds over the Amazon, Geophys. Res. Lett., 31, L24212, doi:10.1029/2004GL021188, 2004.

Correia, F. W. S., Alvalá, R. C. S., and Manzi, A. O.: Modeling the impacts of land cover change in Amazonia: a regional climate model (RCM) simulation study, Theor. Appl. Climatol., 93, 225244, 2007.

Crutzen, P. J. and Andreae, M. O.: Biomass burning in the tropics: Impact on atmospheric chemistry and biogeochemical cycles, Science, 250, 1669-1678, 1990.

Cutrim, E., Martin, D. W., and Rabin, R.: Enhancement of cumulus clouds over deforested lands in Amazonia, B. Am. Meteorol. Soc., 76, 1801-1805, 1995.

Davidi, A., Koren, I., and Remer, L.: Direct measurements of the effect of biomass burning over the Amazon on the atmospheric temperature profile, Atmos. Chem. Phys., 9, 8211-8221, doi:10.5194/acp-9-8211-2009, 2009.

Dubovik, O., Holben, B. N., Eck. T. F., Smirnov, A., Kaufman, Y. J., King, M. D., Tanré, D., and Slutsker, I.: Variability of absorption and optical properties of key aerosol types observed in worldwide locations, J. Atmos. Sci., 59(3), 590-608, 2002.

Durieux, L., Machado, L. A. T., and Laurent, H.: The impact of deforestation on cloud cover over the Amazon arc of deforestation, Remote Sens. Environ., 86(1), 132-140, 2003.

Feingold, G., Remer, L. A., Ramaprasad, J., and Kaufman, Y. J.: Analysis of smoke impacts on clouds in Brazilian biomass burning regions: An extension of Twomey's approach, J. Geophys. Res., 106(D19), 22907-22922, doi:10.1029/2001JD000732, 2001.

Feingold, G., Jiang, H., and Harrington, J. Y.: On smoke suppression of clouds in Amazonia, Geophys. Res. Lett., 32, L02840, doi:10.1029/2004GL021369, 2005.

Friedl, M. A., Sulla-Menashe, D., Tan, B., Schneider, A., Ramankutty, N., Sibley, A., and Huang., X.: MODIS Collection 5 global land cover: Algorithm refinements and characterization of new datasets, Remote Sens. Environ., 114(1), 168-182, 2010.

Gao, B.-C. and Kaufman, Y. J.: Water vapor retrievals using Moderate Resolution Imaging Spectroradiometer (MODIS) 
near-infrared channels, J. Geophys. Res., 108(D13), 4389, doi:10.1029/2002JD003023, 2003.

Giglio, L.: Characterization of the tropical diurnal fire cycle using VIRS and MODIS observations, Remote Sens. Environ., 108(4), 407-421, 2007.

Gunn, R. and Phillips, B. B.: An experimental investigation of the effect of air pollution on the initiation of rain, J. Meteorol., 14, 272-280, 1957.

Henderson-Sellers, A., and Gornitz, V.: Possible climatic impacts of land cover transformations, with particular emphasis on tropical deforestation, Climatic Change, 6(3), 231-257, 1984.

Holben, B. N., Eck, T. F., Slutsker, I., Tanré, D., Buis, J. P., Setzer, A. Vermote, E., Reagan, J. A., Kaufman, Y. J., Nakajima, T., Lavenu, F., Jankowiak, I., and Smirnov, A.: AERONET - A federated instrument network and data archive for aerosol characterization, Remote Sens. Environ., 66(1), 1-16, 1998.

Jacobson, M. Z.: Control of fossil-fuel particulate black carbon and organic matter, possibly the most effective method of slowing global warming, J. Geophys. Res., 107(D19), 4410, doi:10.1029/2001JD001376, 2002.

Jacobson, M. Z.: Effects of externally-through-internally-mixed soot inclusions within clouds and precipitation on global climate, J. Phys. Chem. A., 110(21), 6860-6873, 2006.

Kalnay, E., Kanamitsu, M., Kistler, R., Collins, W., Deaven, D., Gandin, L., Iredell, M., Saha, S., White, G., Woollen, J., Zhu, Y., Leetmaa, A., Reynolds, R., Chelliah, M., Ebisuzaki, W., Higgins, W., Janowiak, J., Mo, K. C., Ropelewski, C., Wang, J., Jenne, R., and Joseph, D.: The NCEP/NCAR 40-Year Reanalysis Project. B. Am. Meteorol. Soc., 77, 437-471, 1996.

Kaufman, Y. J. and Fraser, R. S.: The effect of smoke particles on clouds and climate forcing, Science, 277, 1636-1639, 1997.

Kaufman, Y. J. and Koren, I.: Smoke and pollution aerosol effect on cloud cover, Science, 313, 655-658, 2006.

Kaufman, Y. J. and Nakajima, T.: Effect of Amazon smoke on cloud microphysics and albedo - Analysis from satellite imagery, J. App. Meteorol., 32(4), 729-744, 1993.

Kaufman, Y. J., Tanré, D., and Boucher, O.: A satellite view of aerosols in the climate system, Nature, 419, 215-223, 2002.

Kaufman, Y. J., Koren, I., Remer, L. A., Rosenfeld, D., and Rudich, Y.: The effect of smoke, dust, and pollution aerosol on shallow cloud development over the Atlantic Ocean, P. Natl. Acad. Sci., 102(32), 11207-11212, 2005a.

Kaufman, Y. J., Remer, L. A., Tanré, D., Li, R.-R., Kleidman, R., Matoo, S., Levy, R., Eck, T. M., Holben, B. N., Ichoku, C., Martins, J. V., and Koren, I.: A critical examination of the residual cloud contamination and diurnal sampling effects on MODIS estimates of aerosol over ocean, IEEE T. Geosci. Remote, 43(12), 2886-2897, 2005b.

Khain, A., Rosenfeld, D., and Pokrovsky, A.: Aerosol impact on the dynamics and microphysics of deep convective clouds, Q. J. Roy. Meteorol. Soc., 131(611), 2639-2663, 2005.

King, M. D., Menzel, W. P., Kaufman, Y. J., Tanré, D., Gao, B.C., Platnick, S., Ackerman, S. A., Remer, L. A., Pincus, R., and Hubanks, P. A.: Cloud and aerosol properties, precipitable water, and profiles of temperature and humidity from MODIS, IEEE T. Geosci. Remote, 41(2), 442-458, 2003.

Knohl, A. and Baldocchi, D. D.: Effects of diffuse radiation on canopy gas exchange processes in a forest ecosystem, J. Geophys. Res., 113, G02023, doi:10.1029/2007JG000663, 2008.
Koren, I., Kaufman, Y. J., Remer, L. A., and Martins, J. V.: Measurement of the effect of Amazon smoke on inhibition of cloud formation, Science, 303, 1342-1345, 2004.

Koren, I., Kaufman, Y. J., Rosenfeld, D., Remer, L. A., and Rudich, Y.: Aerosol invigoration and restructuring of Atlantic convective clouds, Geophys. Res. Lett., 32, L14828, doi:10.1029/2005GL023187, 2005.

Koren, I., Remer, L. A., and Longo, K.: Reversal of trend of biomass burning in the Amazon, Geophys. Res. Lett., 34, L20404, doi:10.1029/2007GL031530, 2007.

Koren, I., Martins, J. V., Remer, L. A., and Afargan, H.: Smoke invigoration versus inhibition of clouds over the Amazon, Science, 321, 946-949, 2008.

Koren, I., Feingold, G., and Remer, L. A.: The invigoration of deep convective clouds over the Atlantic: aerosol effect, meteorology or retrieval artifact?, Atmos. Chem. Phys., 10, 8855-8872, doi:10.5194/acp-10-8855-2010, 2010.

Levy, R. C., Remer, L. A., Kleidman, R. G., Mattoo, S., Ichoku, C., Kahn, R., and Eck, T. F.: Global evaluation of the Collection 5 MODIS dark-target aerosol products over land, Atmos. Chem. Phys., 10, 10399-10420, doi:10.5194/acp-10-10399-2010, 2010.

Lin, J. C., Matsui, T., Pielke Sr., R. A., and Kummerow, C.: Effects of biomass-burning-derived aerosols on precipitation and clouds in the Amazon Basin: A satellite-based empirical study, J. Geophys. Res., 111, D19204, doi:10.1029/2005JD006884, 2006.

Martins, J. A., Silva Dias, M. A. F., and Gonçalves, F. L. T.: Impact of biomass burning aerosols on precipitation in the Amazon: A modeling case study, J. Geophys. Res., 114, D02207, doi:10.1029/2007JD009587, 2009.

Matsui, T., Beltrán-Przekurat, A., Niyogi, D., Pielke Sr., R. A., and Coughenour, M.: Aerosol light scattering effect on terrestrial plant productivity and energy fluxes over the eastern United States, J. Geophys. Res., 113, D14S14, doi:10.1029/2007JD009658, 2008.

Meskhidze, N., Remer, L. A., Platnick, S., Negrón Juárez, R., Lichtenberger, A. M., and Aiyyer, A. R.: Exploring the differences in cloud properties observed by the Terra and Aqua MODIS Sensors, Atmos. Chem. Phys., 9, 3461-3475, doi:10.5194/acp-93461-2009, 2009.

Myhre, G., Stordal, F., Johnsrud, M., Kaufman, Y. J., Rosenfeld, D., Storelvmo, T., Kristjansson, J. E., Berntsen, T. K., Myhre, A., and Isaksen, I. S. A.: Aerosol-cloud interaction inferred from MODIS satellite data and global aerosol models, Atmos. Chem. Phys., 7, 3081-3101, doi:10.5194/acp-7-3081-2007, 2007.

Nakajima, T. and King, M. D.: Determination of the optical thickness and effective particle radius of clouds from reflected solar radiation measurements. Part I: Theory, J. Atmos. Sci., 47(15), 1878-1893, 1990.

Negri, A. J., Adler, R. F., Xu, L., and Surratt, J.: The impact of Amazonian deforestation on dry season rainfall, J. Climate, 17(6), 1306-1319, 2004.

Nobre, C. A., Sellers, P. J., and Shukla, J.: Amazonian deforestation and regional climate change, J. Climate, 4(10), 957-988, 1991.

Nobre, C. A., Mattos, L. F., Dereczynski, C. P., Tarasova, T. A., and Trosnikov, I. V.: Overview of atmospheric conditions during the Smoke, Clouds, and Radiation-Brazil (SCAR-B) field experiment, J. Geophys. Res., 103(D24), 31809-31820, doi:10.1029/98JD00992, 1998.

Platnick, S., King, M. D., Ackerman, S. A., Menzel, W. P., Baum, 
B. A., and Riedi, J. C.: The MODIS cloud products: Algorithms and examples from Terra, IEEE T. Geosci. Remote, 41(2), 459473, 2003.

Polcher, J. and Laval, K.: The impact of African and Amazonian deforestation on tropical climate, J. Hydrology (Amsterdam), 155, 389-405, 1994.

Ramanathan, V., Chung, C., Kim, D., Bettge, T., Buja, L., Kiehl, J. T., Washington, W. M., Fu, Q., Sikka, D. R., and Wild, M.: Atmospheric brown clouds: Impacts on South Asian climate and hydrological cycle, P. Natl. Acad. Sci., 102(15), 5326-5333, 2005.

Remer, L. A., Kaufman, Y. J., Holben, B. N., Thompson, A. M., and McNamara, D.: Biomass burning aerosol size distribution and modeled optical properties, J. Geophys. Res., 103(D24), 3187931891, doi:10.1029/98JD00271, 1998.

Remer, L. A., Kaufman, Y. J., Tanré, D., Matoo, S., Chu, D. A., Martins, J. V., Li, R.-R., Ichoku, C., Levy, R. C., Kleidman, R. G., Eck, T. F., Vermote, E., and Holben, B. N.: The MODIS aerosol algorithm, products and validation, J. Atmos. Sci., 62(4), 947-973, 2005.

Roderick, M. L., Farquhar, G. D., Berry, S. L., and Noble, I. R.: On the direct effect of clouds and atmospheric particles on the productivity and structure of vegetation, Oecologia, 129, 21-30, 2001.

Rosenfeld, D., Lohmann, U., Raga, G. B., O’Dowd, C. D., Kulmala, M., Fuzzi, S., Reissell, A., and Andreae, M. O.: Flood or drought: How do aerosols affect precipitation?, Science, 321, 1309-1313, 2008.

Roy, S. B. and Avissar, R.: Impact of land use/land cover change on regional hydrometeorology in Amazonia, J. Geophys. Res., 107(D20), 8037, doi:10.1029/2000JD000266, 2002.

Salomonson, V. V., Barnes, W. L., Maymon, P. W., Montgomery, H. E., and Ostrow, H.: MODIS - Advanced facility instrument for studies of the Earth as a system, IEEE T. Geosci. Remote, 27(2), 145-153, 1989.

Seemann, S., Li, J., Menzel, P., and Gumley, L. E.: Operational retrieval of atmospheric temperature, moisture, and ozone from MODIS infrared radiances, J. Appl. Meteor., 42(8), 1072-1091, 2003.

Segal, M., Avissar, R., McCumber, M. C., and Pielke, R. A.: Evaluation of vegetation effects on the generation and modification of mesoscale circulations, J. Atmos. Sci., 45(16), 2268-2293, 1988.

Squires, P.: The microstructure and colloidal stability of warm clouds, Part I. The relation between structure and stability, Tellus, 10, 256-271, 1958.

Twomey, S., The influence of pollution on the shortwave albedo of clouds, J. Atmos. Sci., 34(7), 1149-1152, 1977.
Wang, J., Bras, R. L., and Eltahir, E. A. B.: The impact of observed deforestation on the mesoscale distribution of rainfall and clouds in Amazonia, J. Hydrometeorol., 1(3), 267-286, 2000.

Wang, J., Chagnon, F. J. F, Williams, E. R., Betts, A. K., Renno, N. O., Machado, L. A. T., Bisht, G., Knox, R., and Bras, R. L.: Impact of deforestation in the Amazon basin on cloud climatology, P. Natl. Acad. Sci., 106(10), 2670-2674, 2009.

Wen, G., Marshak, A., and Cahalan, R. F.: Impact of 3-D clouds on clear sky reflectance and aerosol retrieval in a biomass burning region of Brazil, IEEE Geosci. Remote, 3(1), 169-172, 2006.

Wilcox, E. M., Harshvardhan, and Platnick, S.: Estimate of the impact of absorbing aerosol over cloud on the MODIS retrievals of cloud optical thickness and effective radius using two independent retrievals of liquid water path, J. Geophys. Res., 114, D05210, doi:10.1029/2008JD010589, 2009.

Williams, E., Rosenfeld, D., Madden, N., Gerlach, J., Gears, N., Atkinson, L., Dunnemann, N., Frostrom, G., Antonio, M., Biazon, B., Camargo, R., Franca, H., Gomes, A., Lima, M., Machado, R., Manhaes, S., Nachtigall, L., Piva, H., Quintiliano, W., Machado, L., Artaxo, P., Roberts, G., Renno, N., Blakeslee, R., Bailey, J., Boccippio, D., Betts, A., Wolff, D., Roy, B., Halverson, J., Rickenbach, T., Fuentes, J., and Avelino, E.: Contrasting convective regimes over the Amazon: Implications for cloud electrification, J. Geophys. Res., 107(D20), 8082, doi:10.1029/2001JD000380, 2002.

Winker, D. M., Pelon, J. R., and McCormick, M. P.: The CALIPSO mission: spaceborne lidar for observation of aerosols and clouds, Proc. SPIE, 4893(1), 1-11, doi:10.1117/12.466539, 2003.

Yu, H., Liu, S. C., and Dickinson, R. E.: Radiative effects of aerosols on the evolution of the atmospheric boundary layer, J. Geophys. Res., 107(D12), 4142, doi:10.1029/2001JD000754, 2002.

Yu, H., Fu, R., Dickinson, R. E., Zhang, Y., Chen, M., and Wang, H.: Interannual variability of smoke and warm cloud relationships in the Amazon as inferred from MODIS retrievals, Remote Sens. Environ., 111(4), 435-449, 2007.

Zhang, Y., Fu, R., Yu, H., Dickinson, R. E., Juarez, R. N., Chin, M., and Wang, H.: A regional climate model study of how biomass burning aerosol impacts land-atmosphere interactions over the Amazon, J. Geophys. Res., 113, D14S15, doi:10.1029/2007JD009449, 2008.

Zhang, Y., Fu, R., Yu, H., Qian, Y., Dickinson, R., Silva Dias, M. A. F., da Silva Dias, P. L., and K. Fernandes, "Impact of biomass burning aerosol on the monsoon circulation transition over Amazonia, Geophys. Res. Lett., 36, L10814, doi:10.1029/2009GL037180, 2009. 